\title{
Complex Use of the Water Spring Istog
}

\author{
Sali Fazliu ${ }^{1}$ and Enkelejda Gjinali ${ }^{2}$ \\ 1. Department of Water Recourses Management, University of Pristine for Civil Engineering, Pristine 10000, Republic of Kosova \\ 2. Department of Environmental Engineering, Polytechnic University of Tirana, Tirana 1000, Albania
}

\begin{abstract}
While living in the century of crisis (of energy and water), more focus should be given on renewable energy. Since Kosovo is more limited in hydro-energy resources than the neighboring countries, it is essential to study them and put to use more efficiently. Subject of this study is Istog spring as it is the most important spring of Mokra Gora together with Vrella and White Drino. The spring is analyzed as a complex resource on water economy providing: fish (trout), potable water, water for irrigation and hydro-energy (currently not in function). The focus of the study remains the hydro-energetic component, not just a revitalization process but as an upgrade of the existing facility to increase the capacity by 2-3 times. This study is based on information selection and processing regarding detailed technical and economic analysis providing a method for other springs that will be studied in the future. Two technical solutions to the problem are provided as the best economical and technical solution. Solution 1 has one level and a calculated flow of $7.5 \mathrm{~m}^{3} / \mathrm{s}$ and consists generally of renovation works on existing facilities; Solution 2 plans the construction of another level $3 \mathrm{~m}$ lower than the existing one, increasing so both the hydro-power capacity and implementation cost for the project. Both solutions provide little to no impact on the spring main attributes. The valley ecology will not be influenced because the water after HPP (Hydro Power Plant) will be flowing in its own bed. After this study, Istog spring will be more attractive to donors and will contribute in improvement of energetic structure in Kosovo that for the time being is poor in hydro component.
\end{abstract}

Key words: Water, hydro-energy, environment engineering, complex use and sustainable management, HPP (Hydro Power Plant).

\section{Introduction-Current State of the Spring and Compositions on the "Istog" Spring Hydrology System}

\subsection{Current State of the Spring and Possible Changes for Rational Use}

1.1.1 Principals, Obstacles of the Hydropower System

Energy, water sectors and other public services suffer from long-term neglect in management, maintenance and investment in the physical capital. The most important parts of the system are approaching the end of their shelf-life. They are all under the theoretical capacity and there are large gaps in water supply and particularly in the hydropower system.

The hydropower system is based on the establishment principle as a stable supplier of

Corresponding author: Sali Fazliu, master of Technical Sciences, main research fields: environmental engineering and managing water resources. self-effective management services, providing unbiased and reliable public services supply that meet the standards. Developing and managing water sources systems involves making decisions. Water sources systems typically provide a variety of economic, environmental and ecological services [1].

Consumers have not accepted yet the responsibility for payment of public services they use and that poses an obstacle to making progress towards the free market.

De The Istog spring is a facility comprising of a few elements that have undergone several changes in the course of its use (Figs. 1 and 2). There have been changes made throughout its structure until reaching its current state. The schemes of the flow intake are performed at two levels (Fig. 2).

The inflow composition is an arched weir of diameter $40.00 \mathrm{~m}$, length $53.00 \mathrm{~m}$, height $8.00 \mathrm{~m}$.

The catchment facility in the Istog spring is in good condition, both the integral structure and the cumulative water amount (Fig. 3). It is difficult to 


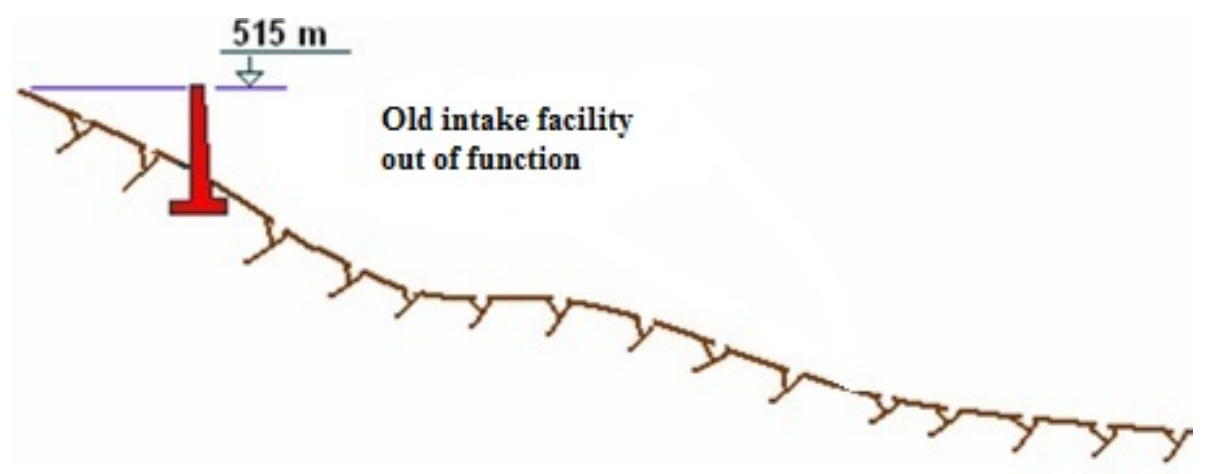

Fig. 1 Out of function in the 515 m quota.

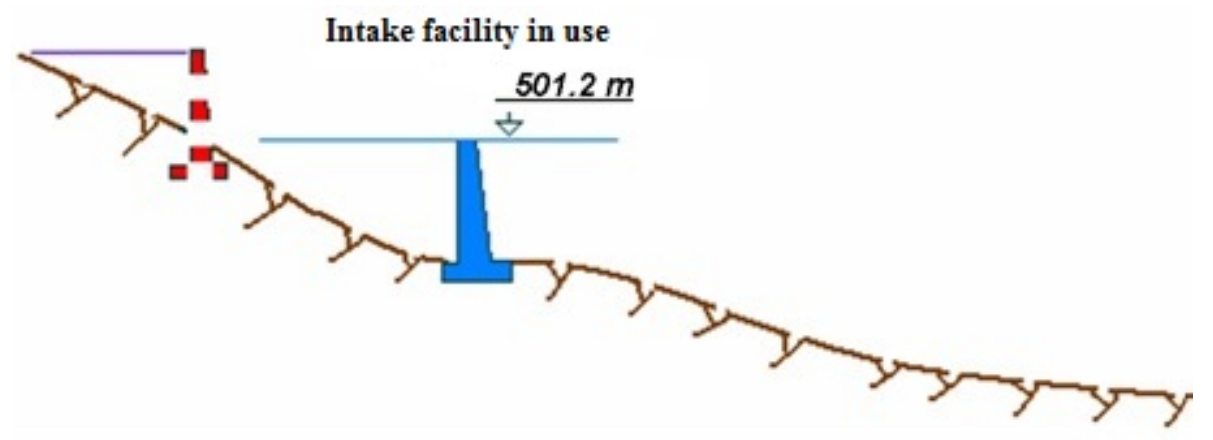

Fig. 2 The scheme in use in $\mathbf{5 0 1 . 2} \mathrm{m}$ quota.

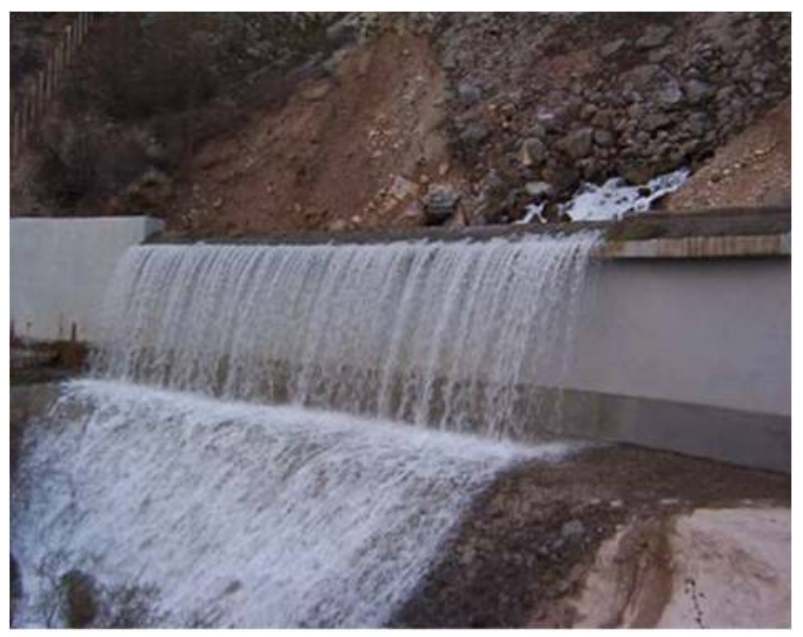

Fig. 3 Photo of dam in catchment facility.

make any changes in this facility. These changes will bring about the deterioration of the work regime of the spring itself.

The solution required for the catchment of the water amount overflow is required at the lowest level, establishing another water catchment facility, to collect overflow water from the main facility as shown in Fig. 3.

\subsubsection{Possible Changes on Inflow Composition}

There is a small difference between quota of the inflow facility and the height of the water outlet from the spring, which stipulates the elevation of the weir height, leading to the flooding of the spring and the deterioration of its own regime.

In order to use the non-accessible water from this composition, an inflow facility should be build at a level slightly below the current facility (see Fig. 4 for two-level exploitation).

\subsubsection{Kosovo Energy System}

There is only one supplier of electricity services in Kosovo, KEK (Kosovo's Energy Corporation). The main priorities are emergency repairs and maintenance to support as much as possible the power generation system yearly. Thus, the basis of the energy system in Kosovo is the thermo-element.

In terms of this, it is the best opportunity to raise the issue of non-usage of water power in Kosovo even though, in comparison to e.g. Albania, water resources and consequently hydropower reserves are smaller. 


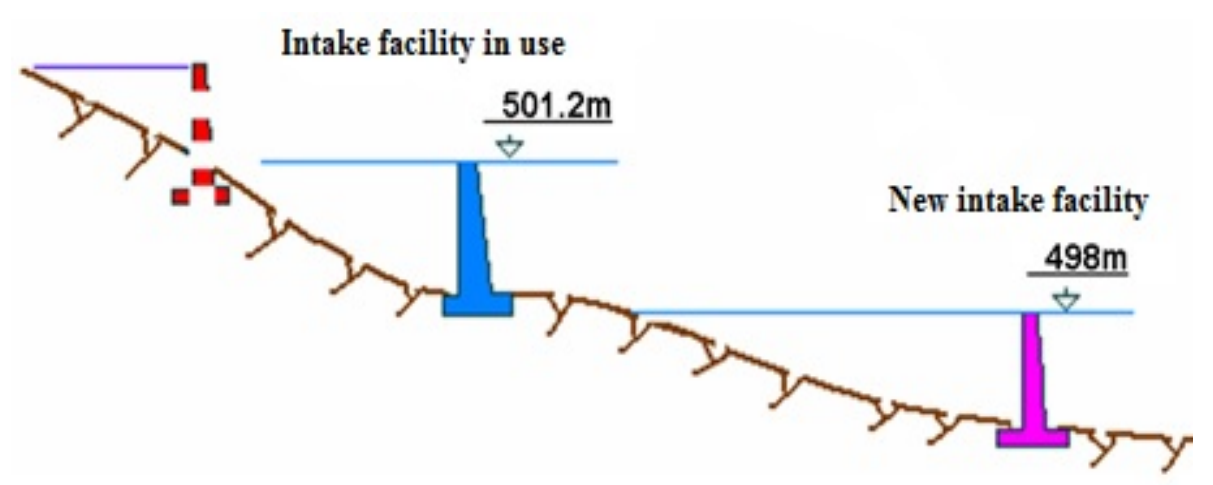

Fig. 4 The new scheme that would use all the amount of water.1.2 Current State of HPP (Hydro Power Plant) and Its Constituent Facilities.

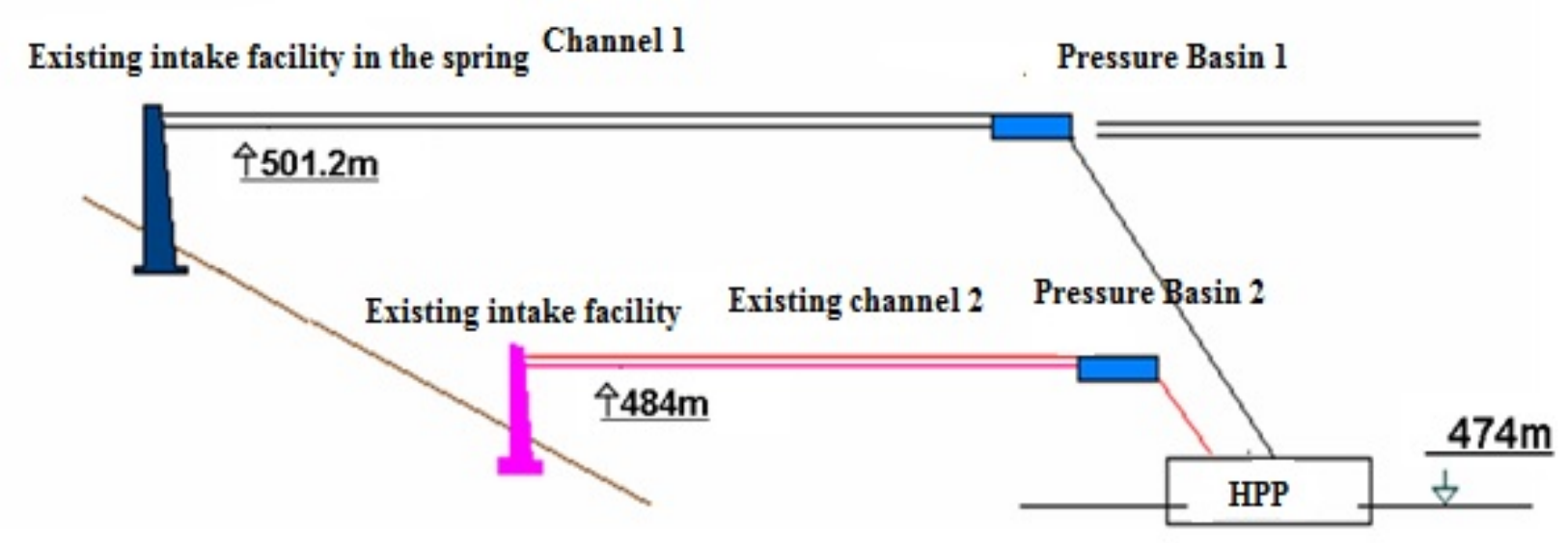

Fig. 5 Current hydropower scheme.

1.2.2 Current State of HPP and Its Constituent Facilities

The current scheme has been built in two levels (Fig. 5). The HPP building is located at $474 \mathrm{~m}$ quota where the use is made at the first level with $10.00 \mathrm{~m}$ incidence.

The current use scheme comprises channel 1, flowing water from catchment facility to the P.B. (Pressure Basin) 1 using the incidence of $380 \mathrm{~m}$ longitude.

Catchment facility in channel 2 to the P.B. 2 using the incidence of $10.00 \mathrm{~m}, 135 \mathrm{~m}$ longitude [2]. The water from the two pressure basins flows to HPP through a pipeline.

1.2.3 Channel of Water Inflow to the P.B. 1

This channel performs a double function. It is used in agriculture between June and September and for hydropower the rest of the months throughout the year. The water amount in the channel is $2.00 \mathrm{~m}^{3} / \mathrm{sec}$. The channel was totally reconstructed, bringing it to the parameters required by the two sectors (Figs. 6 and 7).

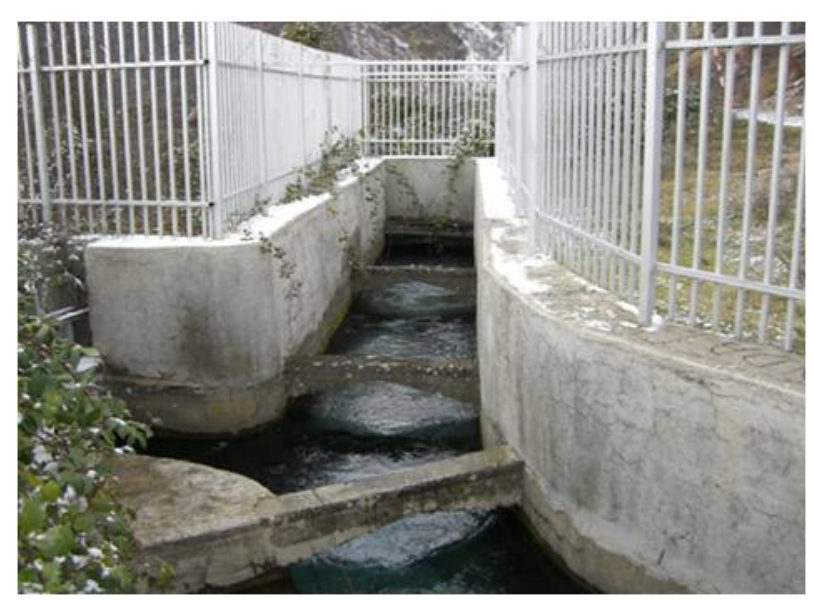

Fig. 6 Photo of water transport channel. 


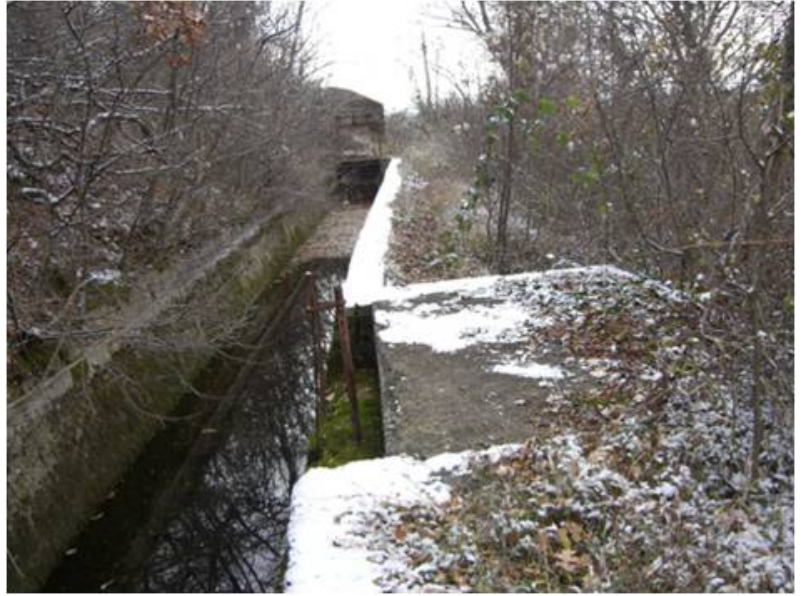

Fig. 7 Existing channel.

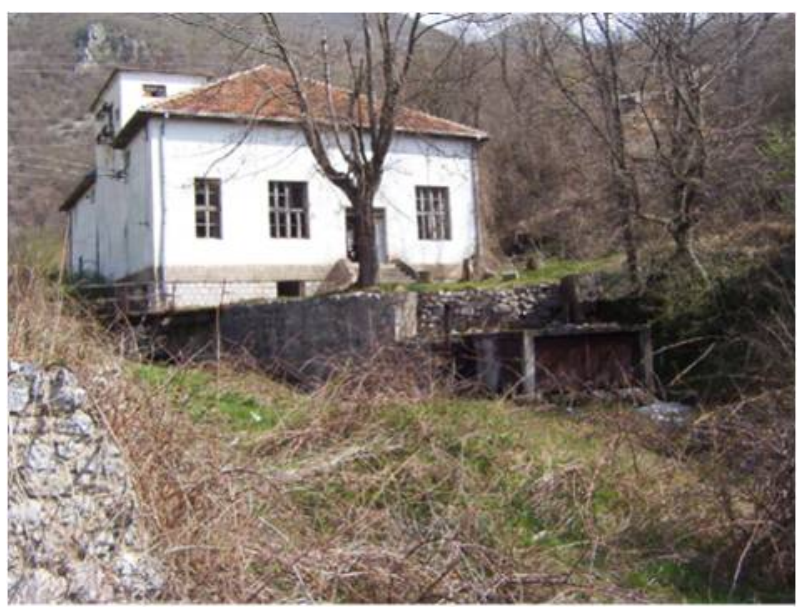

Fig. 8 Photo of hydropower building.

\subsubsection{HPP Building}

From the physical standpoint, the HPP building is a solid structure (see Fig. 8). Considering also its current state of high parameters and with an internal architecture, capable of withstanding the further use and starting from the HPP building-the optimal facility parameters on the energy and economic basis will be retrieved.

1.2.5 Pipeline Network of Water Intake to the HPP

The entire pipeline systems are completely non-operational and depreciated, and they could not be made operational (Fig. 9). These pipelines will be replaced with the investments to be made.

\subsubsection{Old Turbine Type}

There are two turbines in the HPP building (Figs. 10 and 11). They are non-operational due to serious depreciation and lack of maintenance.

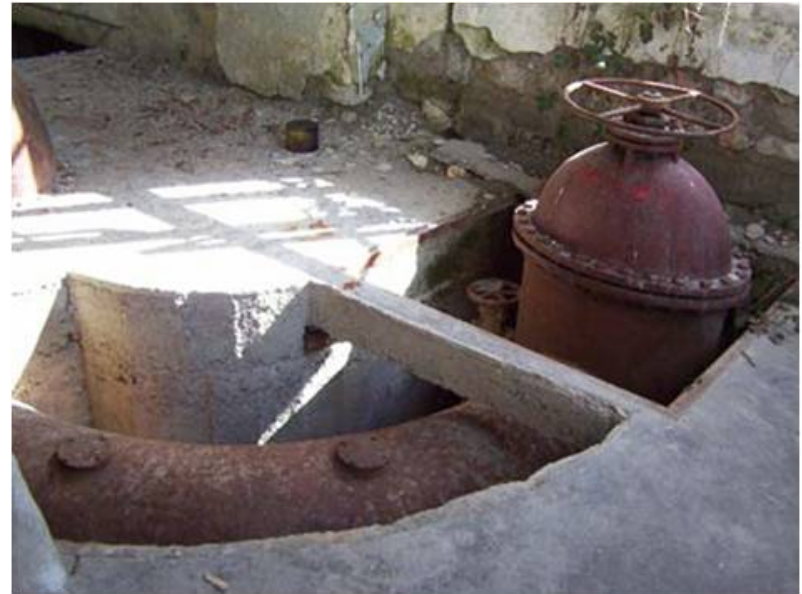

Fig. 9 Amortized pipeline.

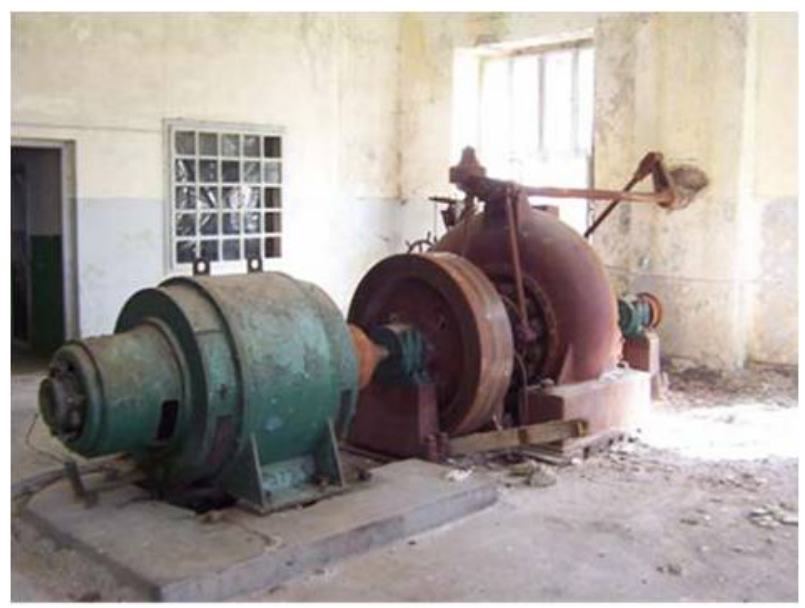

Fig. 10 Turbine out of function.

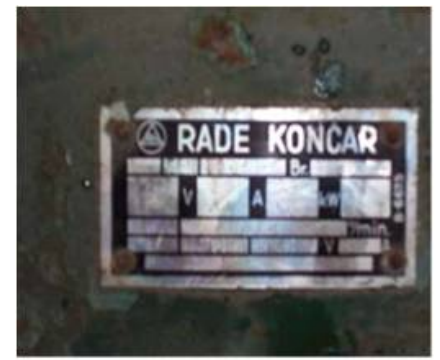

RADE KONCAR, S 1004-8 $400 \mathrm{KVA}, \operatorname{COS} \varphi=0.8,680 \mathrm{~A}$,

$750 \mathrm{rrot} / \mathrm{min}$

RADE KONCAR 905-12

$60 \mathrm{KVA}, 230 \mathrm{~A}, \cos \varphi=0.8$,

$500 \mathrm{rrot} / \mathrm{min}$

Fig. 11 Properties of the existing turbine.

These turbines are physically out of work and it would be impossible making them again operational or that could be achieved at very high costs and very low unjustified efficiency in the conditions of nowadays energy market.

1.2.7 Channel of Water Outflow from HPP

The channel is located on the left side of the HPP building and it is not concrete lined, although it is able to withstand the amount of water used. 


\subsubsection{Channel of Water Inflow to the Fish Farms}

Upon water outflow from HPP, the water, with an intake composition, flowed in through the concrete lined channel to the fish farm reserve (Fig. 12).

\subsubsection{Istog River Valley}

Following the HPP building and the intake water composition for the fish reserve, the water permeates quietly through the valley of the Istog river (Fig. 13).

Generally, there are no erosion problems on river banks, which are mostly protected by trees and protective measures against the erosion occurrence. Such phenomena could be observed in the downstream where frequent flooding occurs.

\subsubsection{Possible Changes of the Facility}

In order to utilize the maximum amount of entire water flowing into the spring, after meeting the basic needs of water customers or users from this spring, various solutions on energy utilization of surplus water have been examined.

Carrying out the necessary comparative analysis, the most effective solutions for the effective maximum use were brought to attention.

The proposed new one-step scheme is shown in Fig. 14.

Two-scale scheme 2 (Fig. 15) by changing the current scheme, the first scale at $501.2 \mathrm{~m}$ quota with the current channel and the second scale at $498 \mathrm{~m}$ quota with steel pipeline with $315 \mathrm{~m}$ length is shown in Fig. 15.

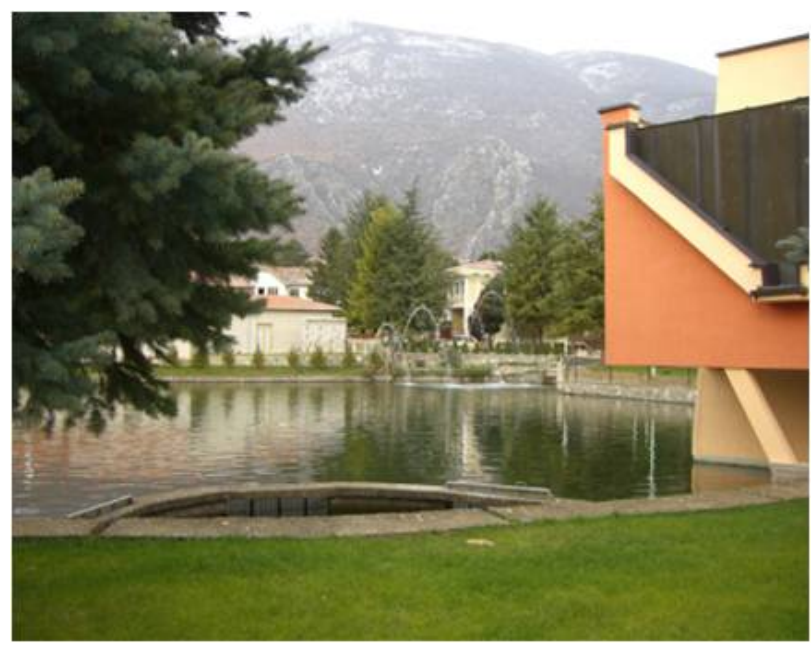

Fig. 12 Reserve of trout in Istog.

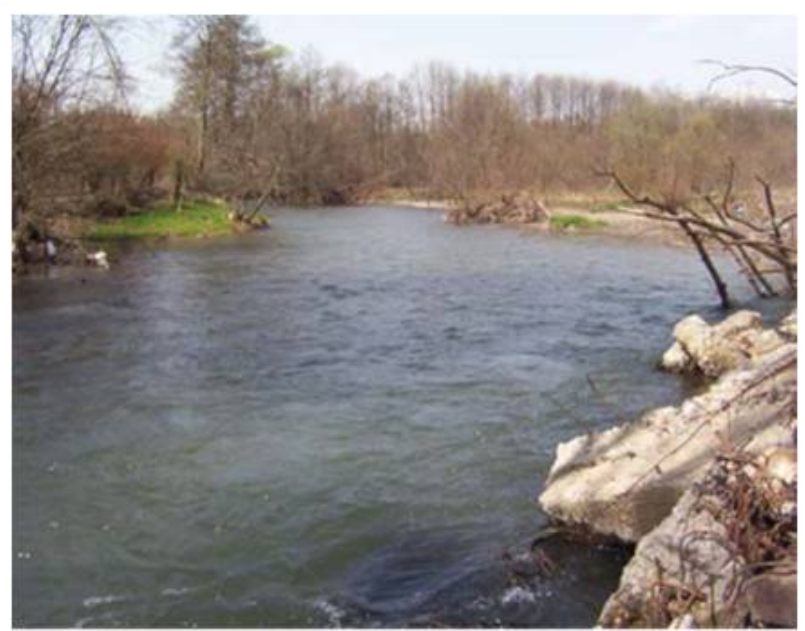

Fig. 13 Istog river valley.

Channel 1

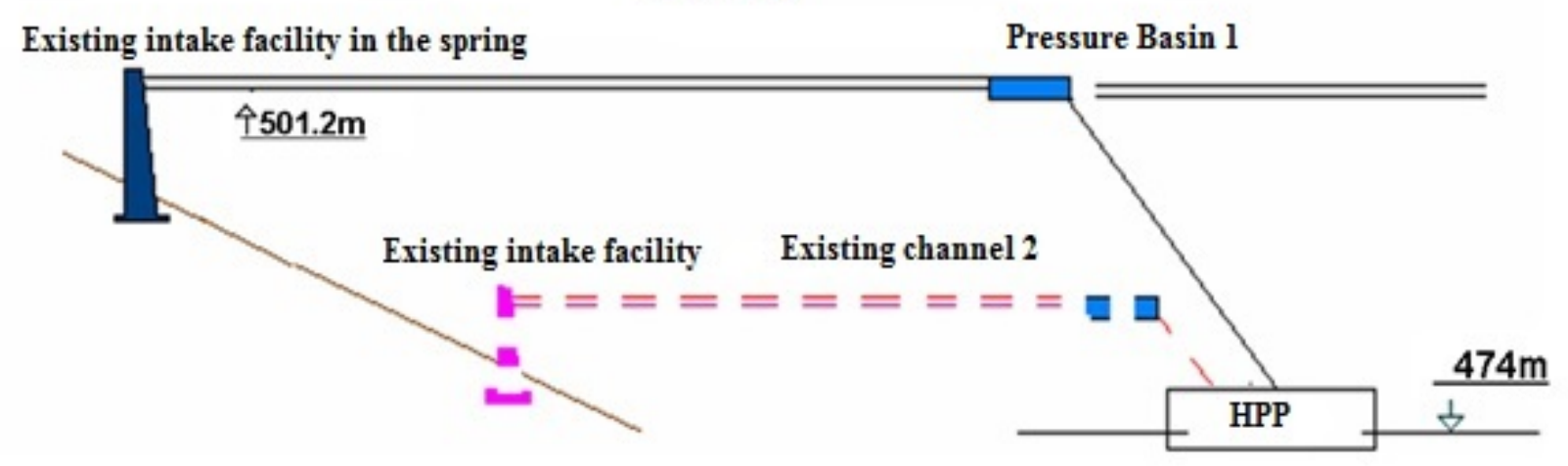

Fig. 14 Scheme with one degree of exploitation. 


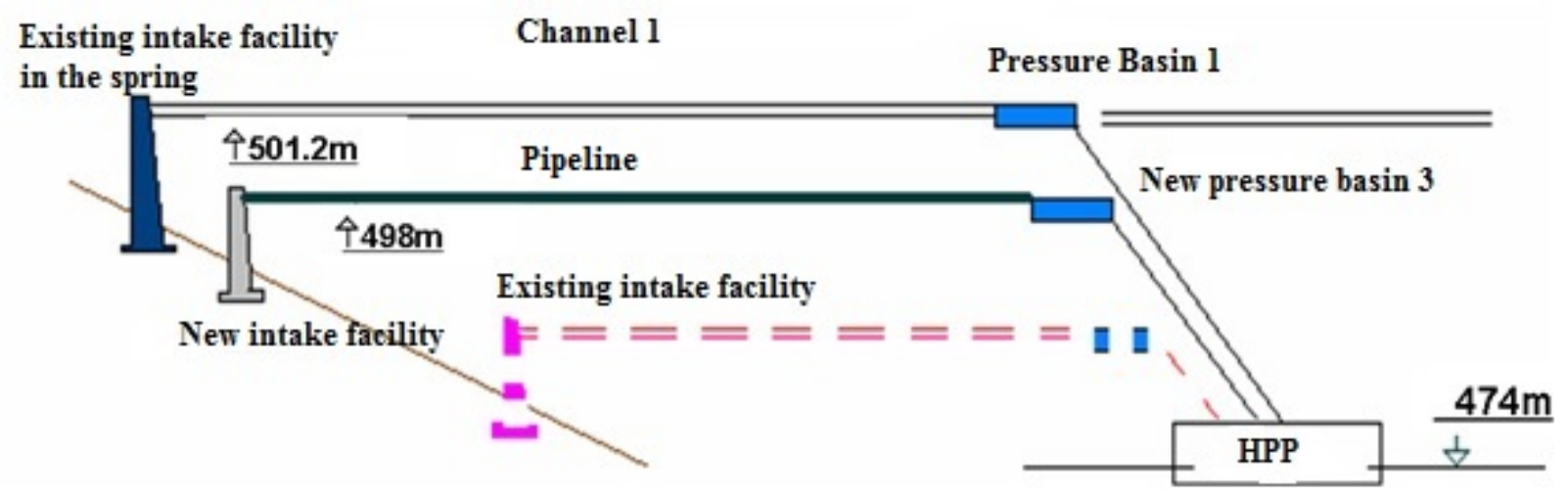

Fig. 15 Scheme with two degree of exploitation.

\section{Hydrological Study on the "Istog" Spring}

\subsection{Hydrology of the Istog Spring}

The hydrological study aims at recognizing and evaluating the overall water potential of the country and the laws of this potential distribution in space and time. The utilization of the hydrographic water network for the needs of economic and cultural development must be preceded in order to recognize this value, without allowing the abundant waters of streams and rivers, being a gift of nature, to flow in vain, without utilizing their usefulness for hydropower, irrigation, water supply of population and industry, recreation etc..

The aim of this paper, relying on the processing and homogenization of a multi-annual comprehensive hydrometric material for the period 1938-1992, was to assess both the watercourse of the Istog underground spring and its relation to the physical-geographic factors of the catchment basin. The watercourse is the most important element of a water resource. It also determines, better than any other element, the ability of the resource to be used for different purposes.

Waters of the hydrographic network of the Istog spring are widely used for drinking water supply to population, irrigation of agricultural lands, industry, energy, fish farming, etc..

2.1.1 Physical-Geographic Conditions of the Catchment Basin of the "Istog" Spring

The Istog spring is one of the main underground springs of the Kosovo hydrographic network. The hydrological regime of the spring is closely related to physical-geographic characteristics of the catchment basin.

The main physical-geographic characteristics of the catchment basin, affecting the hydrological regime of this spring are as:

- Geographic expansion to the catchment basin;

- Relief;

- Hydrography;

- Geology;

- Pedology;

- Tectonics;

- Vegetation cover;

- Geographic distribution of climate elements.

2.1.2 Geographic Expansion to the Catchment Basin

The catchment basin that forms the Istog Basin is located on the northern part of Dukagjini plateau, between the parallels $42^{\circ} 40^{\prime}$ and $42^{\circ} 70^{\prime}$ of the northern latitude and the $30^{\circ} 21^{\prime}$ and $30^{\circ} 20^{\prime}$ meridian, $42^{\circ}$ eastern latitude [3]. It includes approximately $1 / 9$ of the entire surface of the plane. The northern part of Istog river basin lies in Accursed Mountains and a good part at Dry Mountains. Its altitude reaches 1,758 $\mathrm{m}$ at the peak grape, followed by Dry Mountains in the north-western part, with the highest peak of 2,154 $\mathrm{m}$ above the sea level. It lies entirely in the territory of Kosovo, with the general flow course from north-west to south. Located in the south of the "Mokra Gora" Mountain (the Wet Mountain), the Iber river lies in the north over the mountains, in the underground spring 
Vrelle. The basin is $53 \%$ mountainous and $47 \%$ field area. The surface of the catchment basin is $440 \mathrm{~km}^{2}$ and the river basin is $216 \mathrm{~km}^{2}$. The basin has very convenient connections to the second and third category routes, located in the southern and central part of the basin.

\subsubsection{Relief}

The configuration features of the catchment basin of the Istog spring are determined by the geographical expansion of the basin area. The altitude of the spring in $520 \mathrm{~m}$ quota above the sea level shows that this spring collects waters of a territory with an emphasized mountainous character. The highest point is about $1,500 \mathrm{~m}$ above the sea level. The expansion of the basin creating the Istog underground spring is $76 \mathrm{~km}^{2}$, and altimetric position over $1,500 \mathrm{~m}$. Its area is $52 \mathrm{~km}^{2}$ at $1,000-1,500 \mathrm{~m}$ quota about $22 \mathrm{~km}^{2}$, under $1,000 \mathrm{~m}$ with $2 \mathrm{~km}^{2}$ area, karstic part of the catchment area of $6 \mathrm{~km}^{2}$, feeding the Istog spring [4].

\subsubsection{Hydrography}

The hydro-graphic area of the Istog spring catchment basin consists of a completely underground network. This area is characterized by small springs flowing to its main effluent, which is the Istog spring itself and consisting of two adjacent springs. In various periods, there are fluctuations of water quantities in these springs. During the period of inflow measurements, $\mathrm{Q}=(1.19-4.9) \mathrm{m}^{3} / \mathrm{sec}$ are observed, the minimum inflow rate is recorded between September to October $1933(1.6-1.8) \mathrm{m}^{3} / \mathrm{sec}$ which continued for about 50 days and the maximum inflow in 1936 is about $6.6 \mathrm{~m}^{3} / \mathrm{sec}$ [5]. The annual volume flowing into Istog is $(75-126) \times 106 \mathrm{~m}^{3}$. The use of the spring is complex. It is used for drinking water supply, agriculture and trout reserve. It was also used for hydro-electricity in the past.

In regards to the water used for HPP, there is a possibility in taking more water and at higher levels.

The Istog spring is the first spring in the Dukagjini hydrographic network, joining other effluents which are generally underground springs of the Vrella spring, the White Drino spring, Bistrica of Peja, Bistrica of Decani, creating the White Drino river, which percolates to Albania.

This network is considered as the richest one with groundwater basins. The comparison of hydrological conditions of the hydrographic network shows that they have made the accumulation and rational use of water resources possible, land protection from flooding, water systematization in terms of agricultural intensification, etc.

2.1.5 Assessment of Hydrology in the Catchment Basin Forming "Istog" Underground Basin

As a result of climatic factors, the regime of flow distribution throughout the year in the Istog spring is largely formed by rainfalls, soil surface factors, mainly by the relief of geological formation.

The first observations carried out by the department of Peja water measurements belong to the years 1933-1940. Measurements were made by an engineer called Burovic, whose values are reliable because the measurements were made with overflow facility.

Figs. 1 and 2 show annual flow course of the years 1933 to 1940 , and 27 years for recorded measurements.

Fig. 3 shows the evolution of the average flow of 27 years.

Maximum and minimum values were recorded from the observations made for the years 1933-1940 (Table 1) and 1957-1959 (Fig. 16).

Maximum annual inflow $\mathrm{Q}_{\max }=4.0 \mathrm{~m}^{3} / \mathrm{sec}$ [6].

2.1.6 Geology

From the previous studies, it was concluded that this pond was built entirely of thick plaque limestone. Karst springs were formed as a result of geological formation. This composition has conditioned a radial extension of the small karst pits and troughs of 1,500 $\mathrm{m}$ thickness, on which a flavio-dolomite broad plane is formed.

Two corrugated directions were combined in this section: the direction of characteristic abbreviations table on Accursed Mountains and karstic rocks direction, 
Table 1 Average monthly inflow 1933-1940.

\begin{tabular}{|c|c|c|c|c|c|c|c|c|c|c|c|c|}
\hline & & \multicolumn{5}{|c|}{ Monthly avg. inflow 1933-1940 } & \multicolumn{5}{|c|}{ avg. $3.09 \mathrm{~m}^{3} / \mathrm{sec}$} & \\
\hline Month & I & II & III & IV & $\mathrm{V}$ & VI & VII & VIII & IX & $\mathrm{X}$ & $\mathrm{XI}$ & XII \\
\hline Inflow $\left(\mathrm{m}^{3} / \mathrm{sec}\right)$ & 2.72 & 2.75 & 2.96 & 3.19 & 3.57 & 3.53 & 3.3 & 3.12 & 2.84 & 2.88 & 3.05 & 3.09 \\
\hline
\end{tabular}

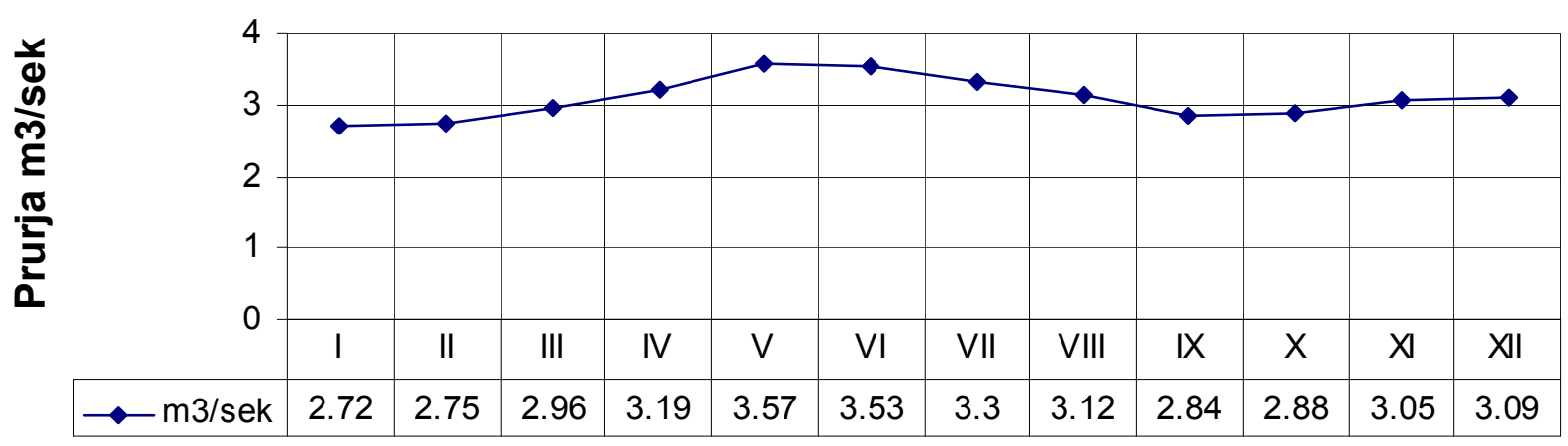

Fig. 16 Average monthly flows 1933-1940.

which is known as dynamic management, characteristic for the Paleozoic formations. In general, they dominate the limestone rocks composed of $\mathrm{MgCO}_{3}$ magnesium, $\mathrm{Ca}$ calcium and dolomite.

This block represents the highest and the most magnificient part of "Dukagjini", the Kosovo Alps, situated in the center of them.

\subsubsection{Pedology}

The surface of the catchment basin of the Istog spring, for its own meridian extent and rugged relief, in terms of pedological aspect, is formed of different types of soil.

Pasture and carbonated-humus lands are located on the altitude of 1,000-1,200 $\mathrm{m}$ above sea level. These lands, mechanically placed under the pasture alpine and subalpine vegetation, represent the upland surface source. These soils occupy a small area of the total territory of the catchment basin of this spring. Brown forest lands, stretching at 700-1,000 m height above sea level, that are mechanically placed under beech, chestnut, Mediterranean fir vegetation etc. represent about $18 \%$ of the forested area.

These soils are permeable and of high hydro-capacity. These lands are distinguished by low content of humus. For the most part, the soil cover or the humus layer is very shallow or absent. Consequently, these lands are more easily subject to the erosion process, as due to the superficial mechanical action, they detach more easily from the surface of the catchment basin, therefore, large infiltration occurs due to this phenomenon. As a result of the pedologic construction, the catchment basin that forms the Istog spring is generally easily subject to the erosion process.

\subsubsection{Tectonics}

The Dukagjini Plain (Rrafshii Dukagjinit) has gained the shape of its territory in the newer era of geological formation. Its forests started to be formed in the Diogenes corrugation towards east-west and north-south-west alignment. The tectonic predisposition has defined the basic contour elements. Radial movement in this region is reflected in orogenies of the mountainous territory to the west and south. Small and large slides are observed in this area. Since its creation to date the tectonic-geomorphology shape has seen many major modifications and they have lost the shape of the previous initial relief.

Parts of these mountains are not as rugged and harsh as before. Now they are more rounded and increasingly losing their previous shapes.

\subsubsection{Vegetation Cover}

Another characteristic is also the scarce vegetation cover. 
By vegetation cover, the surface of the catchment basin forming the Istog spring is divided into different phytoclimatic areas.

Phytoclimatic area of subalpine pasture is situated in the catchment basin territory and located at $1,000 \mathrm{~m}$ altitude above the sea level.

Shrub area lies at lower altitudes, or in the lower area of the territory.

Beech, oak, phytoclimatic areas lie at $900 \mathrm{~m}$ altitude, and the chestnut, white pine area lie at 700-900 $\mathrm{m}$ above the sea level.

This area covered by vegetation continues merging with the surface of the catchment basin of Vrella. These two underground basins are the main effluents forming the underground basin Lubozhde. Therefore, most of the trees are deciduous and protect land slightly from the action of meteorological agents. Forest massifs are mostly poor, they are rare, not uniformly distributed across the surface, and consequently, they are not able to collect large quantities of water and make the evaporation process intensive.

2.1.10 Geographic Expansion of Climatic Elements

\subsubsection{Climatic Position}

Due to its mountain extent, the surface of the catchment basin falls under the humid sub-tropical belt. Significant climate changes have been observed, expressed in the gradual transition to the average continental climate zone of the Central Europe. The main elements conditioning the climate catchment regime as precipitation, air temperature, humidity, etc. are characterized by an annual course more or less designed, depending on the height of land above the sea level, the geographical scope of the basin from the intensity of atmospheric circulation. The area is characterized by cold winters and long duration. The snow there is an ordinary occurrence, while the height of snow layer reaches up to $2 \mathrm{~m}$.

2.1.10.2 Air and Water Temperature

Air temperature is one of the main factors characterizing the thermal regime of the basin.
Analyzing the dependence of the thermal regime with physical-geographic characteristics of the hydrographic basin territory, a conclusion that in general, there is a connection to some extent between the altitude of the country and the height of air temperature is reached, however, the character is regional in nature. Average lowest annual temperatures observed are $11.3{ }^{\circ} \mathrm{C}$. The main factor of temperature change in this area is altitude and geographical position. It turns out that the coldest month is January and the warmest is June-July.

Average annual water temperature is $7-9^{\circ} \mathrm{C}$.

\subsubsection{Rainfalls}

They are main hydro-meteorological characteristic and their distribution in space and time greatly influence the flow regime, because it directly affects filling up water reserves on the land surface and underground. The main features of the pluviometric regime of a geographic region can be recognized by the average annual values. The part where the Istog catchment basin lies is included in the area characterized by the largest average annual amount of rainfalls, where annual rainfall reach up to 1,500 $\mathrm{mm} /$ year. The largest amount of precipitation falls in December and the lowest in June.

Precipitations in the form of snow fall mainly during winter months, and their sustainability depends on local weather conditions and air temperature.

\subsubsection{Solar Radiation}

Data analysis shows that the intensity of the total radiation for unclouded weather conditions has regular annual performance. The maximum intensity value is in July, and the minimum value in January. Total maximum radiation along the territory is 24.79 $\mathrm{kWh} / \mathrm{m}^{2}$. Minimum falls down to $24.79 \mathrm{kWh} / \mathrm{m}^{2}$.

\section{Environmental Impact}

One of the contemporary issues in the construction of engineering works and in particular of hydro-technical works is the environmental impact study. 
In western practice, there are different methodologies developed to assess the environmental work impact, amongst which is the NNC (National Research Center-Italy) under which the environment is studied by components and factors according to Section 3.1.

\subsection{Natural Constituents}

\subsubsection{Physical Constituents}

The physical constituents are surface waters, ground waters, soils, climate, lithology, geology, air and noises.

\subsubsection{Biological Constituents}

The biological constituents are mammals, fish, amphibians, reptiles, birds, insects, microorganisms, herbal vegetation, shrubs, natural vegetation and crops.

\subsection{Socio-economic Constituents}

The socio-economic constituents are population, exodus, culture, archeology, residential zone, health, safety, industry, trade, services, tourism and agriculture.

This is a current and present methodology in Europe and widely, however it is less known and not used at all in Kosovo and Albania.

Certainly, weirs and reservoirs hydro-technical actions make a contribution to the environment, however, derivation hydropower actions also have an impact, which should be assessed both in positive and negative terms.

The essence lies in the assessment causality-consequence of the interaction work-respective territory.

As seen from Section 3, the main components are component of the natural environment (includes physical and biological component) and socio-economic component.

These components have their own factors, which should be identified and assessed before and after the implementation of the project.

What is important in this methodology is the use of assessment "weight attribute" criteria factor, namely, the impact of the project on each factor is assessed not only for quality, but also for quantity. Thus, each factor is given appropriate relevance in relation to the others, reaching finally an "IQUAM (Final Weighted Environmental Quality Index)".

The main procedural stages of an environmental compatibility study shall be:

(1) Preliminary researches;

(2) Description and identification of actions and factors;

(3) Weighing attribution;

(4) Impact assessment;

(5) Data formatting;

(6) Final assessment.

Meanwhile, in order to reach to IQUAM, the genric environmental structure is developed at four levels as shown in Table 2.

In order to assist the methodical application, the ICOLD (Italian National Commission on Large Dams) has also made the list of designing actions and use of compositions. This list shall be used as a standard in the EIS (Environmental Impact Study).

\subsection{Water Use}

The water use are irrigation, energy, drinking water, regulation of rivers, industrial use, sailing, use against fire, fishing, sport use and environmental various use.

\subsection{Physical Factors}

The physical factors are weir presence, reservoir, water diversion, construction site, dikes, buildings, deforestation, closure, channels and pipeline, water outflows, inflow and diversion actions, transmission lines and unconventional materials.

Table 2 Generic environmental structure levels.

\begin{tabular}{ll}
\hline At level zero & General environment \\
\hline At level I & $\mathrm{X}, \mathrm{Y}, \mathrm{Z}$ systems. \\
At level II & Components for every system \\
At level III & Factors for each component \\
\hline
\end{tabular}




\subsection{Areas of Interest}

The areas of interest are flooded areas, lake banks, water level oscillation in the lake, upper part of river, lower part of river, irrigation channels, ground waters, sea coast and lower part of river connected to the basin.

\subsection{Corrective Actions}

The corrective actions are phology repopulation, guaranteed river flow, tourism development, water level control, infrastructure, reforestation, erosion control, river deepening, weir, outflow, auxiliary weir, compensation reservoir, barriers against floating bodies, basin protection, water treatment, improvement industries, transfer of population and area of protection from avio fauna.

\subsection{Normative Predictions}

The normative predictions are national laws, regional laws, urban regulations, contributions and taxes and immovable property values.

\subsection{Interrelation Factors}

The interrelation factors are: inter-regional reservoirs, inter-municipal reservoirs, benefits for other regions and benefits for other municipalities.

The quality impact assessment is also performed in the order shown in Table 3.

Authors emphasizes that the application of this methodology (in particular the section of relevance assessment-weighing of each factor or component that is based on "pair" factors confrontation under the formulated technique by SAAT (Sanitation Approach Advise and Training) is not simple and certainly, its depth depends also on the stages of the project.

In this case study, several possible estimations have been made, especially qualitatively, without analyzing the quantitative part of the environmental impact. Certainly, this action also requires fulfillment in compliance with the proposed methodology, however this will be implemented in further stages of the
Table 3 Quantity impact assessment

\begin{tabular}{lll}
\hline Type of impact & Symbol & \\
\hline Impact & Positive & + \\
& Negative & - \\
Effect & Irreversible & $\mathrm{P}$ \\
& Reversible & $\mathrm{K}$ \\
Duration & Continuous & $\mathrm{V}$ \\
& Temporary & $\mathrm{P}$ \\
Area of impact & Zonal & $\mathrm{Z}$ \\
\hline
\end{tabular}

study-design on the complex use of this water source.

\section{Energy Development Strategy}

The strategy pursued in the public service sector aims to replace the periodic cycle in emergency aid to a gradual process of a sustainable development. The main goal in the public service sector is the establishment of sustainable providers of public services with effective self-management in defense and the public interest services by providing impartial and credible public procurement, meeting proper health, safety, environmental services standards with reasonable prices for all customers. An important and quantifiable criterion for plan is the economic benefits and costs a plan would entail when it implemented [7].

There is only one provider of electrical services (KEK) in Kosovo. The top priorities are urgent repairs and maintenance to support as much as possible the power generation system for the winter period. There have been extensive studies on long-term capital and operational opportunities and future needs. Detailed reviews have been made on the overall state of the system in all aspects.

Planning has triggered discussions and mid-term and long-term projects on the initiation of a project-a comprehensive study covering a long-term period.

\subsection{HPP Location}

The composition actions of the hydropower node are located on the left side of the Istog river valley (Fig. 17). The inflow composition is $501.2 \mathrm{~m}$ and at $498 \mathrm{~m}$ quote, the channel is directed to 501.2-500.2 


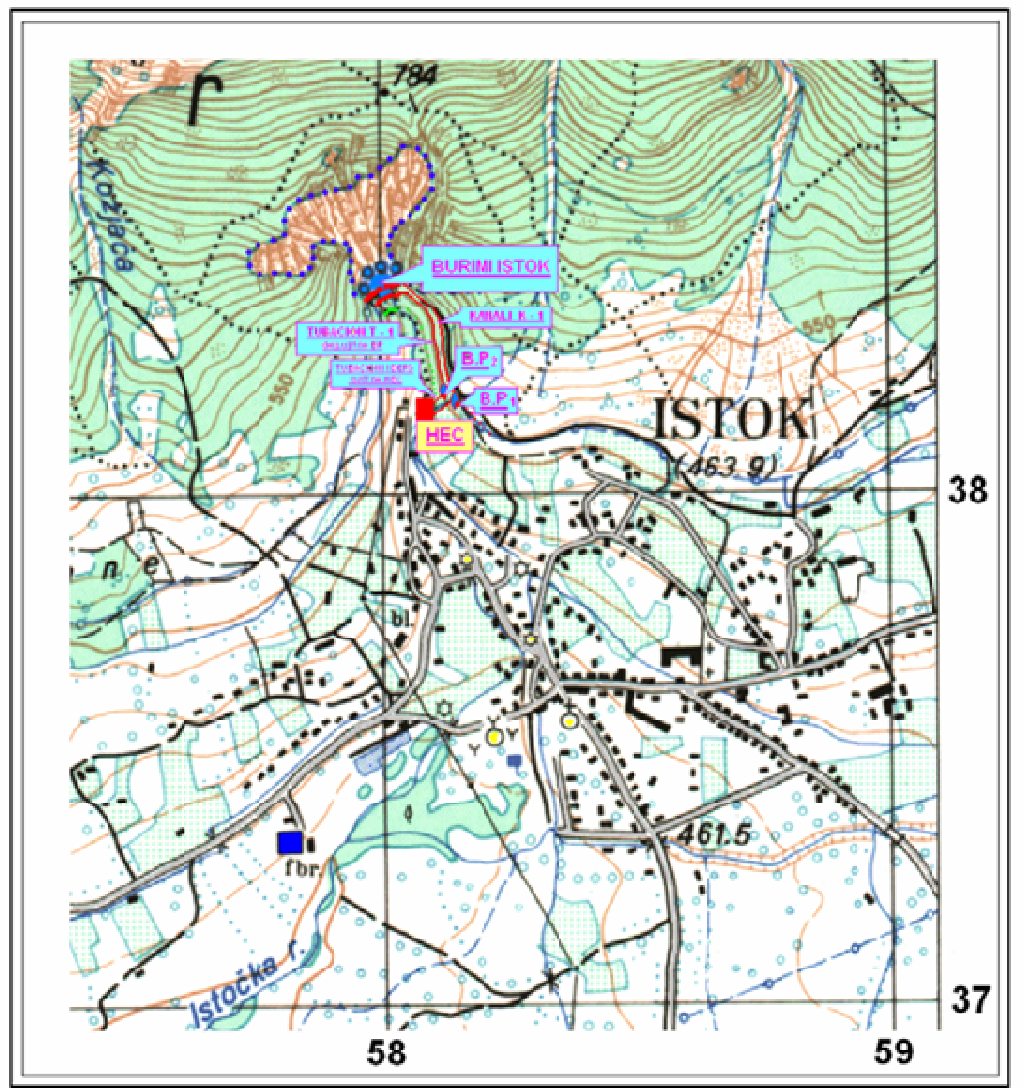

Fig. 17 Location of the hydropower plant.

$\mathrm{m}$ and the pipeline of water delivery to P.B. 3 basin is at $498-497 \mathrm{~m}$ quota. The HPP building is situated at an altitude of $474 \mathrm{~m}$ and is about $4.00 \mathrm{~m}$ above the river valley.

\section{Environmental Impact, Assessments and Counteraction Measures}

\subsection{Structures and Roads}

There were no river deviations during the works which do not affect the valley ecology.

Roads are not affected in this project. During construction and reconstruction, the facilities of other sectors, agriculture, water supply and the fish (trout) farming plant are not affected at all, which inflow water from the HPP water outflow channel. Making the HPP again operational would have a positive effect on the Istog area and beyond because the source is simultaneously fully utilized, electricity is produced and a significant number of workers are employed.

\subsection{Visual Effect}

The visual effect is not affected (Fig. 18) and the reason is that there are many constituent compositions that will be reconstructed with the exception of the second instance that will be a new composition. The solution of pipeline water inflow to the pressure basin has been recognized in order to maintain the visual effect.

\subsection{Flora and Fauna}

Situated in a mountainous area, flora and fauna are the most developed elements both throughout the river valley and forest slopes.

\subsection{Land Use}

Lands in the Istog river valley are in good physical conditions, cultivated in all surfaces, systemized, equipped with all necessary irrigation and drainage systems. 


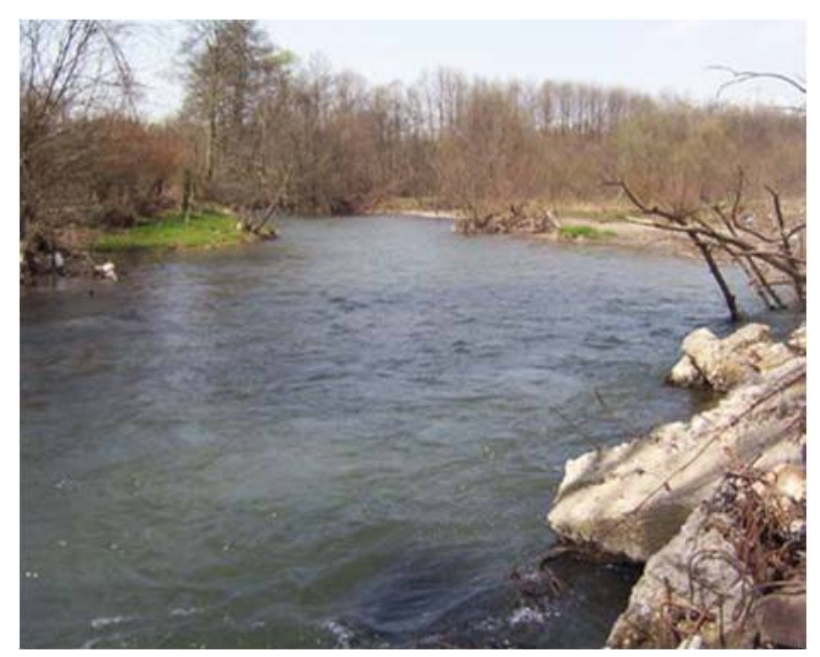

Fig. 18 Visual effect.

\subsection{Population and Employment}

The town of Istog with its surroundings has a relatively small population of 10,000 inhabitants. Employment and labor market is limited because the town of Istog has a limited physical position.

Restoring the HPP, fishing and the development of agriculture, these sectors reduce the unemployment level and raise the living standards.

\section{Conclusions and Recommendations}

From the conducted study, it can be concluded as:

- The results achieved from this study support the general trend in the world to reach a better understanding towards better and complex use of renewable resources. Water resources management is an iterative process of integrated decision-making regarding the uses and modifications of waters and related lands within a geographic region [8];

- Although Kosovo, compared to the neighbor countries, is poor in water resources (hence hydropower resources), it is an urgent task starting and conducting studies as soon as possible on all streams, progressively drafting a master plan in now new conditions, treating water as a vital element in order to avoid emerging crisis in the near future;

- With the presented solutions (without affecting their components of water economy: on water supply of the population, agriculture, fish economy, valley ecology), the Istog source may provide an average annual electricity production of nearly 7 million $\mathrm{kWh}$ with a gross income of about 300,000 euro per year;

- The implementation of this study is extremely easily realized for a very short term;

- It is recommended to colleagues who are in various stages of their doctorate to be involved in similar studies for other water sources, specifically contributing to gradually complete an overview of water and hydropower opportunities of the state of Kosovo. To this regard, the department, faculty in cooperation with relevant local government ministries have a real opportunity to contribute to this nature;

- Authors of this study is aware that his work has flaws but it is a step in the right direction in paving the road for conducting concrete studies and serving Kosovo's economy, creating a foundation where following works will be more profoundly performed from a scientific standpoint.

\section{References}

[1] Loucks, D. P., and Beek, E. V. 2017. Water Sources Systems Planning and Management: An Introduction to Methods, Models and Applications. Springer, 293.

[2] Peja Regional Irrigation Company. 2012. Irrigation for Peja Region. Peja City Annual Work Reports.

[3] Energoprojekt. 1974. Water Solution of Metohija II: Hydrology Metrology. Belgrade: Energoprojekt.

[4] Hydro Meteorological Institute of Kosovo. 2010. Hydrological Yearbook. Prishtina.

[5] Institute for Hydro-economy "Jaroslav Cerni”. 1983. Review of Hydro Economic Base of Kosovo. Belgrade: Institute for Hydro-economy.

[6] Institute for Hydro-economy "Jarosllav Cerni”. 1978. The Required Document, Amount of Water for Irrigation in the Pond of White Drino. Belgrade: Institute for Hydro-economy.

[7] Loucks, D. P., Stedinger, J. R., and Haith, D. A. 1981. Water Source Systems Planning and Analysis. Prentice-Hall, 15.

[8] Simonovic, S. P. 2009. Managing Water Resources. London: UNESCO Publishing, 50. 